\title{
RESEARCH
}

Open Access

\section{Extracellular vesicle mimics made from iPS cell-derived mesenchymal stem cells improve the treatment of metastatic prostate cancer}

Qingguo Zhao, Bo Hai, Jack Kelly, Samuel Wu and Fei Liu*

\begin{abstract}
Background: Extracellular vesicles (EVs) and their mimics from mesenchymal stem cells (MSCs) are promising drug carriers to improve cancer treatment, but their application is hindered by donor variations and expansion limitations of conventional tissue-derived MSCs. To circumvent these issues, we made EV-mimicking nanovesicles from standardized MSCs derived from human induced pluripotent stem cells (iPSCs) with a theoretically limitless expandability, and examined the targeting capacity of these nanovesicles to prostate cancer.

Methods: Nanovesicles are made from intact iPSC-MSCs through serial extrusion. The selective uptake of fluorescently labeled nanovesicles by prostate cancer cells vs. non-tumor cells was examined with flow cytometry. For in vivo tracing, nanovesicles were labeled with fluorescent dye DiR or renilla luciferase. In mice carrying subcutaneous or bone metastatic PC3 prostate cancer, the biodistribution of systemically infused nanovesicles was examined with in vivo and ex vivo imaging of DiR and luminescent signals. A chemotherapeutic drug, docetaxel, was loaded into nanovesicles during extrusion. The cytotoxicities of nanovesicle-encapsulated docetaxel on docetaxel-sensitive and -resistant prostate cancer cells and non-tumor cells were examined in comparison with free docetaxel. Therapeutic effects of nanovesicle-encapsulated docetaxel were examined in mice carrying subcutaneous or bone metastatic prostate cancer by monitoring tumor growth in comparison with free docetaxel.
\end{abstract}

Results: iPSC-MSC nanovesicles are more selectively taken up by prostate cancer cells vs. non-tumor cells in vitro compared with EVs, membrane-only EV-mimetic nanoghosts and liposomes, which is not affected by storage for up to 6 weeks. In mouse models of subcutaneous and bone metastatic PC3 prostate cancer, systemically infused nanovesicles accumulate in tumor regions with significantly higher selectivity than liposomes. The loading of docetaxel into nanovesicles was efficient and did not affect the selective uptake of nanovesicles by prostate cancer cells. The cytotoxicities of nanovesicleencapsulated docetaxel are significantly stronger on docetaxel-resistant prostate cancer cells and weaker on non-tumor cells than free docetaxel. In mouse models of subcutaneous and bone metastatic prostate cancer, nanovesicle-encapsulated docetaxel significantly decreased the tumor growth and toxicity to white blood cells compared with free docetaxel.

(Continued on next page)

\footnotetext{
* Correspondence: fliu@tamu.edu

Institute for Regenerative Medicine, Molecular and Cellular Medicine Department, College of Medicine, Texas A\&M University Health Science Center, College Station, TX 77843, USA
}

(c) The Author(s). 2021 Open Access This article is licensed under a Creative Commons Attribution 4.0 International License, which permits use, sharing, adaptation, distribution and reproduction in any medium or format, as long as you give appropriate credit to the original author(s) and the source, provide a link to the Creative Commons licence, and indicate if changes were made. The images or other third party material in this article are included in the article's Creative Commons licence, unless indicated otherwise in a credit line to the material. If material is not included in the article's Creative Commons licence and your intended use is not permitted by statutory regulation or exceeds the permitted use, you will need to obtain permission directly from the copyright holder. To view a copy of this licence, visit http://creativecommons.org/licenses/by/4.0/. The Creative Commons Public Domain Dedication waiver (http://creativecommons.org/publicdomain/zero/1.0/) applies to the data made available in this article, unless otherwise stated in a credit line to the data. 
(Continued from previous page)

Conclusions: Our data indicate that EV-mimicking iPSC-MSC nanovesicles are promising to improve the treatment of metastatic prostate cancer.

Keywords: Mesenchymal stem cells, Induced pluripotent stem cells, Prostate cancer, Metastasis, Extracellular vesicle mimics, Nanovesicles, Targeted cancer therapy

\section{Background}

Prostate cancer $(\mathrm{PCa})$ is the second most frequent cancer in men and the fifth leading cause of death worldwide [1]. Skeletal metastases occur in more than $80 \%$ of cases of advanced-stage PCa and often become resistant to androgen deprivation therapy and cytotoxic chemotherapies [2]. Despite recent advancements of novel therapies, the relative 5-year survival rate for distant stage $\mathrm{PCa}$ is still $<30 \%$. Nanomedicine of $\mathrm{PCa}$ is a promising direction, but mainstream synthesized nanoparticles cannot efficiently deliver anti-cancer agents into metastatic PCa due to the lack of active targeting capacity and the limited uptake of these nanoparticles by PCa cells $[3,4]$.

Natural extracellular vesicles (EVs) and EV-mimetic nanovesicles (NVs) are taken up by cancer cells more efficiently than synthetic nanoparticles through active endocytosis pathways such as enhanced macropinocytosis (cell drinking) [5]. Moreover, EVs and NVs are favorable drug carriers to overcome the multidrug resistance of cancer cells caused by the increase of drug efflux via hyperactive membrane transporters. Compared with free drugs taken up mainly by passive diffusion through the cell membrane, drugs carried by EVs and NVs are released distal to the cell membrane and therefore less likely to be extruded by membrane transporters [5]. Consequently, the encapsulation of chemotherapy drugs with EVs or NVs dramatically increased drug accumulation and cytotoxicity in multidrug-resistant renal cancer cells (up to 50-fold compared with free drugs) [6], and improved therapeutic effects in animal models of colorectal cancer [7].

Mesenchymal stem cells (MSCs) interact with PCa cells through multiple surface molecules, and EV-mimicking nanoghosts made from bone marrow (BM) MSC membranes showed active PCa-targeting capacity in a mouse model of subcutaneous PCa $[8,9]$. However, nanoghosts cannot deliver cytoplasmic components such as proteins and nucleic acids expressed by MSCs. Moreover, MSCs isolated from tissues such as bone marrow have high donor variations and limited expandability and lose some important biological functions after prolonged expansion [10-14]. Therefore, it is challenging to use tissue-derived MSCs as reliable sources for the large amounts of standardized EV mimics required for further research and future clinical application [15].

To address the cell source issues, we established MSCs from induced pluripotent stem cells (iPSCs) with a theoretically limitless expandability [16]. These iPSCderived MSCs (iPSC-MSCs) are highly consistent in the homing capacities to various cancers and the expression of surface molecules related to cancer targeting [16-18]. The osteogenic potentials of our iPSC-MSCs are superior to BM-MSCs $[16,19]$, while the immunomodulatory capacities are comparable between these two types of MSCs $[20,21]$. We have prepared nanoghosts from membraneonly ghost iPSC-MSCs and nanovesicles from intact iPSCMSCs respectively by serial extrusions [18]. Compared with nanoghosts, iPSC-MSC nanovesicles showed a much higher production yield and a smaller size that is related to better tumor penetration [18]. We report here that iPSC-MSC nanovesicles are capable of targeting human $\mathrm{PCa}$ xenografts in mouse models of subcutaneous and bone metastatic PCa, and significantly enhanced therapeutic effects of docetaxel, a PCa chemotherapy drug, with decreased toxicity to white blood cells.

\section{Methods \\ Cells}

The iPSC-MSCs were recovered from frozen vials of a cell bank that has been characterized extensively including the trilineage differentiation in comparison with bone marrow MSCs from multiple donors $[16,19]$. These cells were plated at a density of 500 cells per square centimeter of growth area in $17 \% \mathrm{FBS} \alpha \mathrm{MEM}$ medium at $37^{\circ} \mathrm{C}$ and $5 \%$ $\mathrm{CO}_{2}$ and passaged upon $70-80 \%$ confluence. The iPSCMSCs at passage 6 with $70-80 \%$ confluency were harvested for all experiments. Human PC3 prostate cancer cells, human smooth muscle cells (SMCs), human umbilical vein endothelial cells (HUVECs), and THP-1 human myeloid cells were purchased from ATCC and expanded following ATCC instructions. PC3 cells were transduced with the lentiviral vectors carrying firefly luciferase 2 (Luc2) and tdTomato [22] at a multiplicity of infection (MOI) of 10 virus particles per cell in the presence of $8 \mu \mathrm{g} / \mathrm{ml}$ polybrene, and tdTomato ${ }^{+}$PC3 cells were sorted by fluorescence-activated cell sorting (FACS) (Supplementary Methods and Fig. S3) for in vivo tracing.

\section{Preparation and in vitro characterization of Dil-labeled nanovesicles}

To prepare fluorescently labeled nanovesicles and nanoghosts for in vitro assays, iPSC-MSCs $\left(1 \times 10^{6} / \mathrm{mL}\right)$ were labeled with $5 \mu \mathrm{l} / \mathrm{mL}$ DiI cellular membrane labeling- 
solution (ThermoFisher, D-282) for $20 \mathrm{~min}$ at $37^{\circ} \mathrm{C}$. For nanoghost preparation, iPSC-MSCs were hypotonically treated with tris-magnesium buffer followed by mild homogenization to make ghost cells without cytosol. Following the published protocols $[7,8,23]$, ghost or intact iPSC-MSCs were extruded through 10, 5, 3, 1.2, and $0.4 \mu \mathrm{m}$ polycarbonate membranes, and nanoghosts or nanovesicles were isolated by ultra-centrifugation for 45 min at $150,000 \times g$ at $4{ }^{\circ} \mathrm{C}$. The sizes of these EV-mimics were analyzed using Nanosight LM 10 Nanoparticle Tracking Analysis System (Malvern). To examine the selective uptake of nanoparticles by PCa cells in vitro, $1 \times$ $10^{10}$ DiI-labeled nanoghosts, nanovesicles, or liposomes (FormuMax, F60103F-DI) were incubated with $1 \times 10^{5}$ PC3 cells, SMCs, or HUVECs in $1 \mathrm{ml}$ DMEM for $15 \mathrm{~min}$, $1 \mathrm{~h}$, or $3 \mathrm{~h}$, then cells were washed with phosphatebuffered saline (PBS) three times and analyzed by flow cytometry for DiI signal. The selective uptake of DiI-labeled nanoparticles by PC3 cells vs. SMCs or HUVECs was quantified as the log odds ratio (LOR) as reported [8].

\section{Preparation and in vitro characterization of nanovesicles labeled with renilla luciferase}

To trace nanovesicle content, we constructed a lentiviral vector encoding cytoplasmic renilla luciferase (rLuc) and GFP under the control of ubiquitous EF1 $\alpha$ and PGK promoter, respectively. The rLuc cDNA was amplified from plasmid pRL Renilla Luciferase reporter vector (Promega) by PCR, linked into BamHI site of PCDH-CMV-MCS-EF1-copGFP (System Biosciences, CD511B-1) backbone, and then cloned again into the EcoRI + NotI site of plasmid backbone pCDH-EF1-MCS-BGH-PGK-GFP-T2A-Puro (System Biosciences, CD550A-1). Lentiviral vectors carrying rLuc and GFP were prepared by transfecting 293T cells (ATCC) with the above pCDH-EF1-mLuc-PGKGFP plasmid with pPACK packaging plasmid mix and concentrated by PEG-it virus precipitation solution (System Biosciences). Human iPSC-MSCs were transduced with the rLuc-GFP lentivirus at an MOI of 10 with $8 \mu \mathrm{g} / \mathrm{ml}$ polybrene, and $\mathrm{GFP}^{+}$cells were sorted by FACS to expand. NVs were reconstructed from non-transduced and $\mathrm{GFP}^{+}$rLuc-transduced iPSCMSCs and absorbed on $4 \mu \mathrm{m}$ aldehyde/sulfate-latex beads (ThermoFisher) to examine GFP expression with FC500 flow cytometer (Beckman Coulter). To determine the correlation between rLuc signal intensities and rLuc-NV numbers before or after uptake by cells, rLuc-NVs were incubated alone or with $1 \times 10^{4}$ / well PC3 cells in 96-wells plate for $3 \mathrm{~h}$ at $37^{\circ} \mathrm{C}$, and the luminescence was measured after incubation with rLuc substrate Coelenterazine (Sigma, $2.5 \mu \mathrm{g} / \mathrm{ml}$ ) for 15 min with a FLUOstar Omega plate reader (BMG LABTECH).

\section{Animals}

Male NU/J athymic nude mice were purchased from the Jackson Laboratory. Subcutaneous and bone metastatic PCa mouse models were generated by injecting $1 \times 10^{5}$ Luc2-PC3 cells subcutaneously at the right flank or $5 \times 10^{4}$ Luc2-PC3 cells intratibially into the right hind leg of these mice at 9 12 weeks old. The animal numbers are 4 mice per group for biodistribution assays and 6 mice per group for assays on therapeutic effects as reported [7, 24]. The in vivo Luc2 signals were imaged weekly with IVIS Lumina III System (PerkinElmer) at $15 \mathrm{~min}$ after subcutaneous injection of DLuciferin (150 ng/g body weight in $100 \mu \mathrm{l}$ PBS).

\section{Biodistribution of nanovesicles in mice carrying PCa}

Nanovesicles for biodistribution assays were labeled with either rLuc inside them or the near-infrared fluorescent dye $\mathrm{DiR}$ (ThermoFisher, D-12731) on their surface as reported [24] with procedures similar to DiI labeling. These nanovesicles were PEGylated as reported [8] by incubating in PBS containing Methoxy-polyethylene glycol (PEG) succinate N-hydroxysuccinimide (Sigma, 85,976) at room temperature for $2 \mathrm{~h}$ with gentle agitation. The PEGylation was stopped by adding $100 \mathrm{mg}$ I-Lysine (Sigma), and then unreacted PEG, excess lysine and reaction by-products were eliminated by buffer exchange over a Micro-Bio Spin P-30 column (Bio-Rad) equilibrated with TM-buffer $(\mathrm{pH}$ 8.6, Sigma). Mice carrying established subcutaneous or bone $\mathrm{PCa}$ were randomly grouped and intraperitoneally (IP) injected with PEGylated DiR-NVs, rLuc-NVs or DiRliposomes (FormuMax, F60203F-DR) at the dose of $1 \times$ $10^{10}$ particles/gram ( $\left.\mathrm{p} / \mathrm{g}\right)$ as optimized for DiR-labeled MSC EVs [24]. The numbers of NVs and liposomes were quantified by nanoparticle tracking analysis with NanoSight NS300 (Malvern). The biodistribution of DiR-labeled liposomes and nanovesicles was examined by in vivo and ex vivo imaging of DiR fluorescence with IVIS Lumina III System (PerkinElmer). For in vivo imaging of rLuc signals, ViviRen substrate $(2 \mu \mathrm{g} / \mathrm{g}$ body weight in $200 \mu \mathrm{l}$ PBS) was IP injected, and luminescent images were taken $15 \mathrm{~min}$ later with IVIS Lumina III System. The intensities of DiR or rLuc signals in tumor and non-tumor regions were quantified with the Living Image software (PerkinElmer).

\section{Preparation and in vitro characterization of docetaxel- nanovesicles (DxI-NVs)}

iPSC-MSCs were pre-incubated with $5 \mu \mathrm{g} / \mathrm{mL}$ Dxl (Sigma, PHR1883) for $24 \mathrm{~h}$ or not pretreated, and then broken down by serial extrusion in the presence of 50 , 100 , or $200 \mu \mathrm{g} / \mathrm{mL}$ Dxl to make Dxl-loaded NVs. The amount of Dxl loaded into NVs was determined by UV spectrometry at $230 \mathrm{~nm}$ as reported [25] using a spectrofluorometer (ThermoFisher). After incubation in $37^{\circ} \mathrm{C}$ PBS containing $10 \%$ pooled human serum (Sigma) or $4{ }^{\circ} \mathrm{C}$ PBS for a series of periods, the supernatant was 
isolated by ultra-centrifugation at $100,000 \times g$ for $90 \mathrm{~min}$ at $4{ }^{\circ} \mathrm{C}$ using Sorvall WX Floor Ultra Centrifuge (Thermo) to measure Dxl release from NV-Dxl by UV spectrometry. Dxl-resistant PC3 cells were established as reported [26]. $5 \times 10^{3} /$ well parent PC3 cells, Dxlresistant PC3 cells, or THP-1 human myeloid cells were seeded into 96-well plates, incubated with empty NVs, NV-Dxl, or free Dxl at a series of concentrations for 72 $\mathrm{h}$, and then analyzed with PrestoBlue Cell Viability Assay (ThermoFisher).

\section{Therapeutic effects of NV-DxI}

Mouse models of subcutaneous and bone metastatic PC3 PCa were established as mentioned above. Sizes of subcutaneous tumors were measured every 4 days with calipers, and tumor volumes were calculated with the modified ellipsoid formula $1 / 2$ (length $\times$ width $^{2}$ ) $[27,28]$. Luc2 signals were imaged weekly and the bioluminescence intensities were quantified with the Living Image software (PerkinElmer). When subcutaneous tumors reached the size of $50 \mathrm{~mm}^{3}$ and Luc2 signals were clearly detectable in the injected leg by in vivo imaging, mice were randomly grouped and injected IP with PBS, free Dxl or PEGylated Dxl-NVs at the dose of $5 \mathrm{mg} / \mathrm{kg}$ body weight twice a week for 3 weeks. The blood was collected at the end point for complete blood count using the VetScan HM5 Color Hematology System (Abaxis).

\section{Statistical analyses}

All statistical analysis and graphical generation of data were done with GraphPad Prism software. Statistical comparisons between two groups were performed with unpaired two tailed Student's $t$ tests. Comparisons involving more than two groups were performed with one-way analysis of variance (ANOVA) followed by the post hoc Bonferroni test. Comparisons involving $\geq 3$ time points and $\geq 3$ different treatments were performed with a repeated measures ANOVA followed by the post hoc Bonferroni test. $P<0.05$ is considered significant. All quantified data were presented as mean \pm SD.

\section{Results}

Nanovesicles made from iPSC-MSCs are more selectively taken up by $\mathrm{PCa}$ cells than nanoghosts and liposomes

We prepared extracellular vesicles (EVs), nanoghosts (NGs), and nanovesicles (NVs) from our iPSC-MSCs cultured under same conditions as reported $[7,8,18,21]$. The mean size of nanovesicles is much smaller and more uniform than nanoghosts and EVs (Fig. S1A), suggesting that nanovesicles might achieve better tumor penetration due to smaller particle size [29]. The yield of nanovesicles is about 3-fold of that of nanoghosts and 6-fold of EVs in term of particle numbers (Fig. S1B). Both nanoghosts and nanovesicles express EV surface markers ALIX and
TSG101 at levels comparable to EVs (Fig. S1C-D). To trace iPSC-MSC EVs, nanoghosts, and nanovesicles in vitro, we labeled them with a lipophilic fluorescent dye DiI [8]. The DiI labeling efficiency was comparable between EVs, nanoghosts, nanovesicles, and commercially available DiI-liposomes, and the DiI signal intensities were in proportion to numbers of these particles [18]. To determine the uptake of these particles by prostate cancer cells vs. non-tumor cells, we incubated DiI-labeled and nonPEGylated liposomes, EVs, nanoghosts, or nanovesicles with human PC3 PCa cells, human smooth muscle cells (SMCs), or human umbilical vein endothelial cells (HUVECs) for $15 \mathrm{~min}, 1 \mathrm{~h}$, or $3 \mathrm{~h}$. After washing, percentages of $\mathrm{DiI}^{+}$cells were determined by flow cytometry, and the selective uptake by PC3 cells was quantified as log odds ratios (LOR) vs. SMCs or HUVECs as reported [8]. The uptake of liposomes by PC3 cells was comparable to non-tumor cells as expected, whereas iPSC-MSC EVs, nanovesicles, and nanoghosts were selectively taken up by PC3 cells vs. either SMCs or HUVECs after various incubation periods (Fig. 1a-c). Despite the same cell source, the PC3-selective uptake of nanovesicles (LOR) is significantly higher than that of EVs and nanoghosts after incubation for 1 or $3 \mathrm{~h}$, which is related to the higher uptake by PC3 cells of nanovesicles than EVs and the lower uptake by non-tumor cells of nanovesicles than nanoghosts (Fig. 1a-c). The selective uptake of nanovesicles by PC3 cells vs. SMCs was validated by confocal microscope imaging of GFP-transduced cells incubated with DiI-labeled nanovesicles for 1 or $3 \mathrm{~h}$ (Fig. S2). We have confirmed that iPSC-MSC nanovesicles maintain their size, charge, and selective uptake by breast cancer cells after prolonged storage [18]. Consistently, after storage at $4{ }^{\circ} \mathrm{C}$ for 1,2 , or 3 weeks or at $-80^{\circ} \mathrm{C}$ for 6 weeks, the selective uptake of iPSC-MSC nanovesicles by PC3 cells vs. SMCs was not significantly decreased compared to fresh nanovesicles resuspended in PBS at $4{ }^{\circ} \mathrm{C}$ overnight (Fig. 1d, e). These data indicate that iPSC-MSC nanovesicles are superior to EVs and nanoghosts for $\mathrm{PCa}$-targeting and maintain $\mathrm{PCa}-$ targeting capacity after storage; therefore we focus on iPSC-MSC nanovesicles for all following experiments.

\section{Systemically infused iPSC-MSC nanovesicles accumulate in subcutaneous PCa with higher efficacy than liposomes} For in vivo biodistribution assays, nanovesicles were firstly labeled with a near-infrared lipophilic fluorescent dye DiR as reported for EVs [24], PEGylated as reported for BM-MSC nanoghosts [8], and compared with DiRlabeled liposomes (FormuMax) PEGylated in the same way as FDA-approved liposomes to deliver a chemotherapy drug (Doxil, 5\% PEG 2000-DSPE) [30]. Subcutaneous xenograft models are widely used for PCa study to facilitate the monitoring of $\mathrm{PCa}$ growth and the harvest of PCa tumors. Nude mice carrying subcutaneous Luc2- 


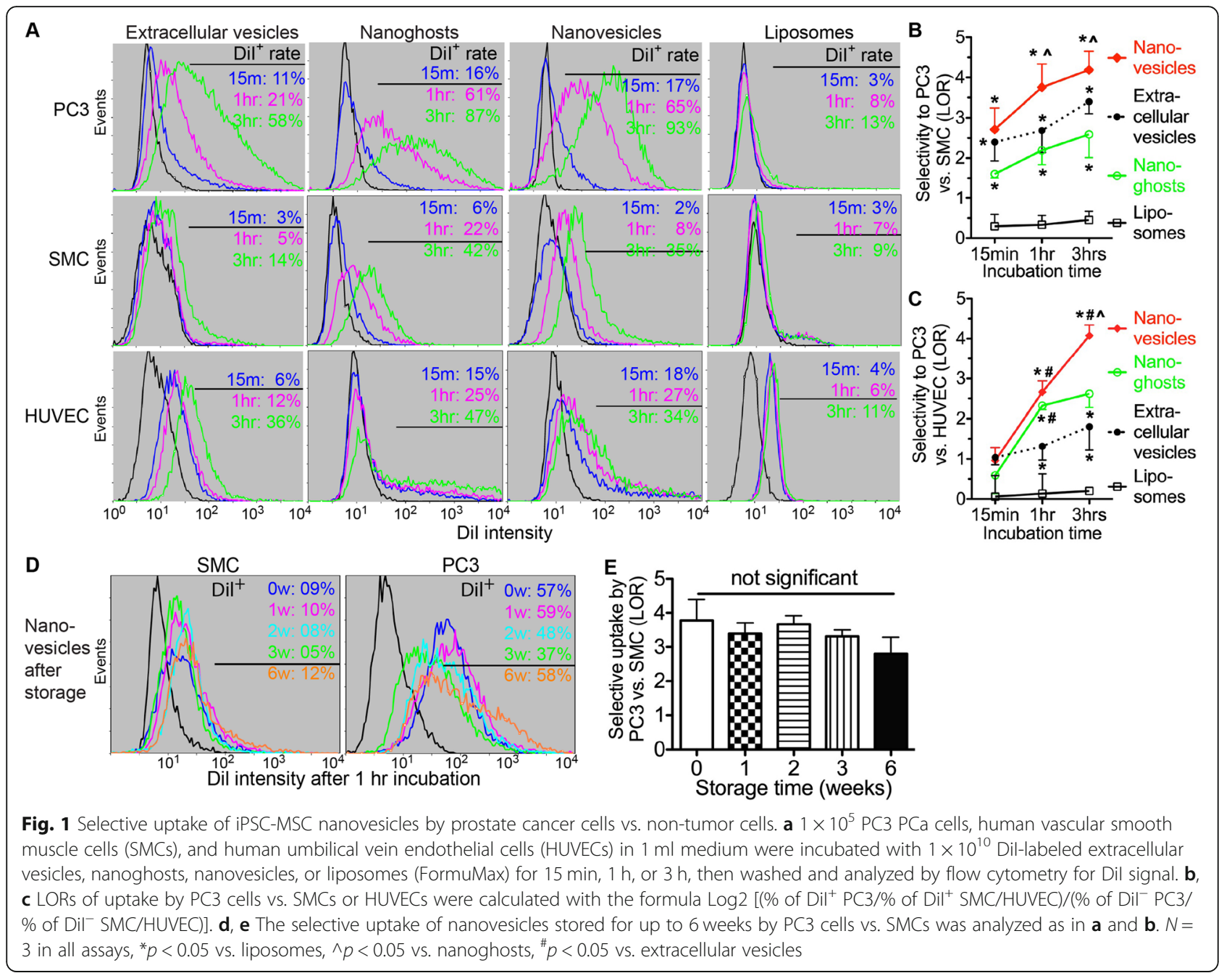

PC3 PCa were randomly grouped and injected intraperitoneally (IP) with DiR-labeled liposomes or nanovesicles. In vivo Luc2 and DiR imaging indicated that DiR signals in Luc2 $^{+}$tumor region were significantly higher in the $\mathrm{NV}$ group 12, 24, and $48 \mathrm{~h}$ after infusion than in the liposome group, while strong DiR signals in both groups were also present in the upper abdomen area containing the mononuclear phagocytic system (MPS) organs such as the liver and spleen (Fig. 2a-c). Tumors and major organs were harvested $24 \mathrm{~h}$ after infusion for ex vivo DiR imaging. The tumor DiR signals were significantly higher in the NV group than in the liposome group, whereas DiR signals in the liver and spleen are comparable high in both groups (Fig. $2 \mathrm{~d}-\mathrm{f}$ ).

Since assays on DiR only reflect the distribution of membrane components of nanovesicles, we then labeled contents of nanovesicles with cytoplasmic renilla luciferase (rLuc) that can be clearly distinguished from Luc2 signals in PC3 cells based on distinct substrates and bioluminescent properties. Nanovesicles were reconstructed form iPSC-MSCs transduced with a lentiviral vector encoding cytoplasmic rLuc and green fluorescent protein
(GFP), and almost all rLuc-labeled NVs express GFP as indicated by flow cytometry assay (Fig. 3a). These rLucnanovesicles were comparable to non-transduced (NT) nanovesicles in size and selective uptake by PC3 cells vs. non-tumor cells (Fig. 3b, c). We then examined the luciferase activity of rLuc-labeled NVs in vitro with or without co-culture with PC3 cells. Under both conditions, the intensities of rLuc signals were correlated to nanovesicle numbers in linear relationships (Fig. 3d, $r^{2}>0.91$ ). These rLuc-nanovesicles were PEGylated and IP injected into mice carrying subcutaneous PC3 tumors. The in vivo imaging indicated that at 12 and $24 \mathrm{~h}$ after NV infusion, strong and localized rLuc signals were present at Luc2 ${ }^{+}$ tumor regions (Fig. 3e-g). Compared with tumor DiR signals, the relative intensity of tumor rLuc signals was higher at 12 and $24 \mathrm{~h}$ after NV infusion but decreased faster. Similar to DiR signals, strong and dispersed rLuc signals were also present in the abdomen area containing MPS organs (Fig. 3e-g). The DiR and rLuc imaging data together indicated the selective accumulation of infused nanovesicles in subcutaneous PCa and MPS organs. 

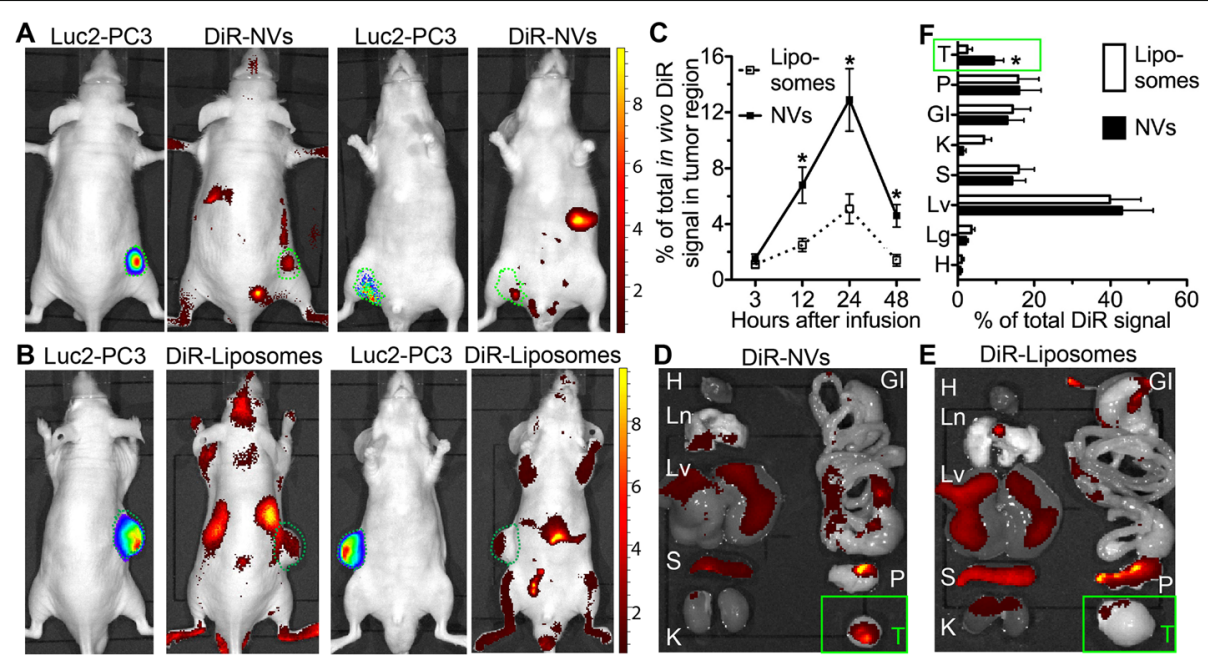

Fig. 2 Biodistribution of systemically infused DiR-NVs in mice carrying subcutaneous prostate cancer. Nude mice carrying subcutaneous Luc2-PC3 tumors were randomly grouped and IP infused with PEGylated liposomes or NVs labeled with DiR. $\mathbf{a}, \mathbf{b}$ The representative in vivo imaging of Luc2 and DiR signals at $24 \mathrm{~h}$ after infusion from both the dorsal and ventral sides. c The relative intensities of in vivo DiR signals in Luc2 ${ }^{+}$tumor region and non-tumor regions were quantified at 3,12,24, and $48 \mathrm{~h}$ after infusion as percentages of total DiR signals. $\mathbf{d}$-f Tumors (T) and organs were collected $24 \mathrm{~h}$ after infusion for ex vivo imaging and consequent quantification. $H$, heart; Ln, lungs; Lv, liver; S, spleen; $K$, kidneys; Gl, gastrointestinal tract; $P$, pancreas. $N=4$ in all assays, ${ }^{*} p<0.05$

\section{Systemically infused iPSC-MSC nanovesicles accumulate in bone metastatic PCa with higher efficacy than liposomes}

The bone metastatic PCa mouse model was generated by intratibial injection of Luc2-PC3 cells into nude mice, and then DiR-labeled NVs or liposomes or rLuc-labeled NVs were injected IP into randomly grouped mice carrying bone metastatic PCa. In vivo DiR imaging indicated that DiR signals in $\mathrm{Luc}^{+}$bone $\mathrm{PCa}$ regions were much stronger in the $\mathrm{NV}$ group than in the liposome group at 12 and $24 \mathrm{~h}$ after infusion, while strong DiR signals in both groups were also present in the upper abdomen area containing the MPS organs (Fig. $4 \mathrm{a}-\mathrm{c}$ ). The ex vivo DiR imaging of tissues harvested $12 \mathrm{~h}$ after the infusion confirmed much higher relative DiR signals within the PCacarrying leg in the NV group than in the liposome group, and also revealed high DiR signals in the liver and spleen comparable between these two groups (Fig. 4d-f). The rLuc imaging confirmed that IP injected rLuc-NVs accumulated in bone metastases despite a much faster decrease of rLuc signals than DiR signals (Fig. 4g-i). These data indicated that systemically injected iPSC-MSC NVs are capable of targeting metastatic $\mathrm{PCa}$ with a selectivity superior to liposomes. However, similar to all other nanoparticles including bone marrow MSC EVs [24] and nanoghosts [8,9], a large portion of the infused NVs is taken up by MPS organs despite the routine PEGylation to increase their stealth, which need be decreased for future applications.

\section{Nanovesicles efficiently encapsulated docetaxel and enhanced its cytotoxic effects on resistant prostate cancer cells}

Docetaxel (Dxl) is a first-line drug for metastatic prostate cancer [31], but its dose is limited by toxicities to non-tumor cells such as myeloid cells [32]. Furthermore, Dxl resistance is common in advanced PCa patients [33]. Based on the protocol for loading Dxl into EVs from tissue-derived MSCs [34], iPSC-MSCs were pretreated with $5 \mu \mathrm{g} / \mathrm{mL}$ Dxl for $24 \mathrm{~h}$ or not pretreated; and then broken down into NVs in solutions containing 50, 100, or $200 \mu \mathrm{g} / \mathrm{ml}$ Dxl as reported for loading a similar drug, paclitaxel, into EV mimics [35]. The maximal Dxl loading into NVs was achieved by extrusion of Dxlpretreated iPSC-MSCs in $50 \mu \mathrm{g} / \mathrm{mL}$ Dxl (Fig. 5a). In comparison to empty NVs, Dxl loading at 50 or $100 \mu \mathrm{g} /$ $\mathrm{ml}$ did not significantly affect the size distribution of NVs (Fig. 5b) and the selective uptake of NVs by PC3 cells vs. SMCs (Fig. 5c, d), whereas Dxl loading at $200 \mu \mathrm{g} / \mathrm{ml}$ slightly increased the NV size and significantly decreased the selective uptake of NVs by PC3 cells. Therefore, we chose NV-Dxl made by extrusion of Dxl-pretreated iPSC-MSCs in $50 \mu \mathrm{g} / \mathrm{mL}$ Dxl for all following experiments. The release kinetics of Dxl from NV-Dxl indicated that in both $4{ }^{\circ} \mathrm{C}$ PBS and $37^{\circ} \mathrm{C}$ serum most Dxl remained inside NVs for up to $48 \mathrm{~h}$ (Fig. 5e). In parent PC3 cells, the cytotoxicity of NV-Dxl was comparable to free Dxl, whereas empty NVs displayed no cytotoxicity at amounts equal to those of NV-Dxl (Fig. 5f). In Dxl-resistant PC3 cells established as reported [26], the cytotoxicity of NV-Dxl was significantly 


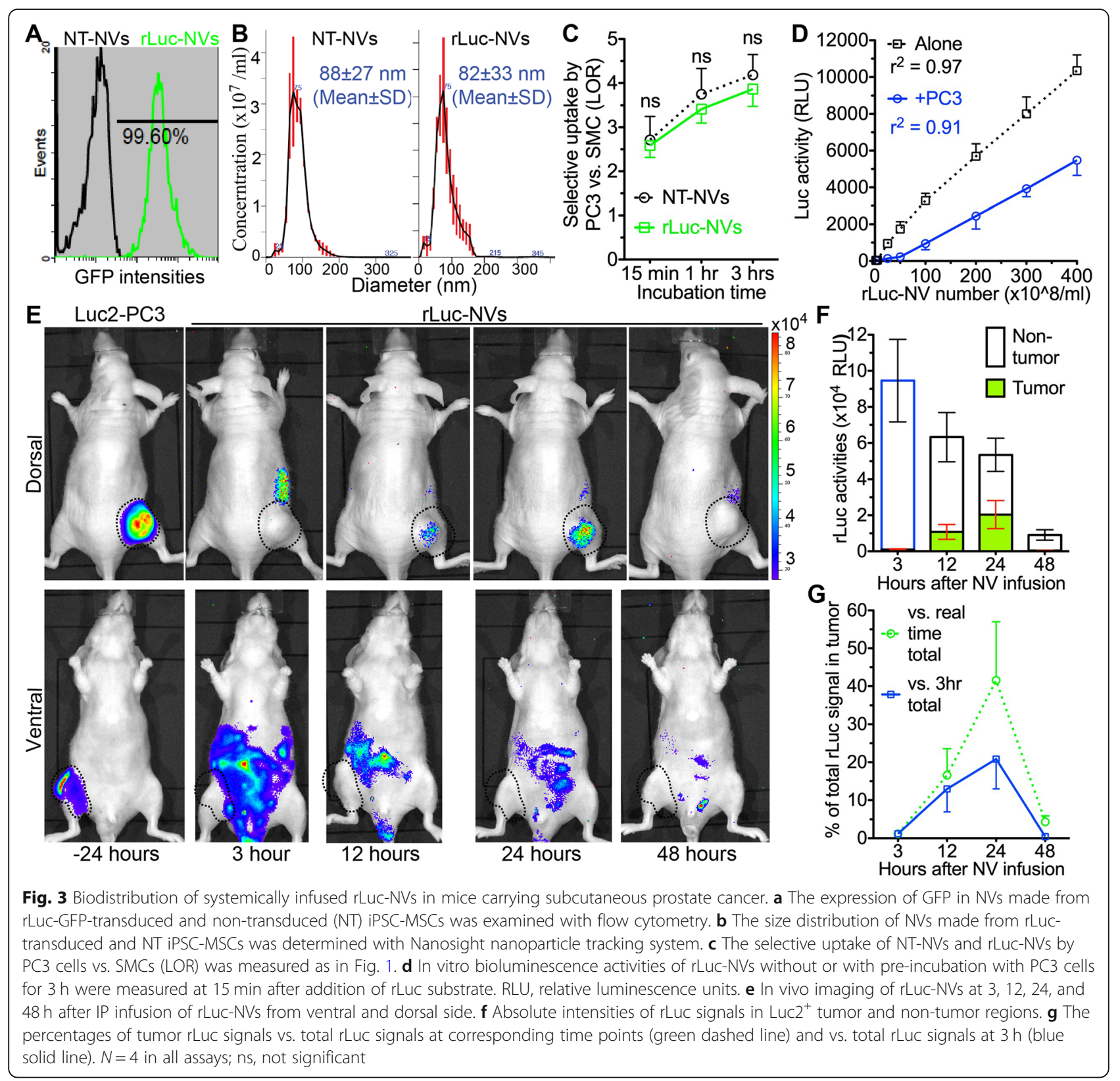

stronger than free Dxl: the half maximal inhibitory concentration (IC50) of free Dxl is higher than $100 \mathrm{ng} / \mathrm{ml}$, whereas that of NV-Dxl is around $30 \mathrm{ng} / \mathrm{ml}$ (Fig. $5 \mathrm{~g}$ ). Dxl frequently causes toxicities to non-tumor cells such as myeloid cells, and the consequent severe neutropenia is a major dose-limiting adverse effect of Dxl [32]. Therefore, we examined the toxicity of NV-Dxl and free Dxl on human THP-1 myeloid cells. As indicated by the viability assay, $\mathrm{NV}$ encapsulation significantly decreased Dxl toxicity on THP-1 cells at concentrations between 3 to $30 \mathrm{ng} / \mathrm{ml}$ (Fig. 5h). These data suggest that NV-Dxl could efficiently overcome Dxl-resistance of PCa in vivo at tolerable doses.
Therapeutic and adverse effects of nanovesicles loaded with docetaxel in the subcutaneous and bone metastatic PC3 PCa mouse models

Both PCa mouse models were generated as mentioned above with Luc2-PC3 cells. When subcutaneous tumors reached the size of $50 \mathrm{~mm}^{3}$ and Luc2 signals were clearly detectable by in vivo imaging, we IP injected PBS, free Dxl or PEGylated Dxl-NVs into randomly grouped mice at the dose of $5 \mathrm{mg} / \mathrm{kg}$ body weight twice a week for 3 weeks. The dose of NV-Dxl was chosen as reported for Dxl carried by synthesized nanoparticles that effectively inhibited the progression of subcutaneous $\mathrm{PCa}$ and reduced hematological toxicity in a mouse model [36]. 


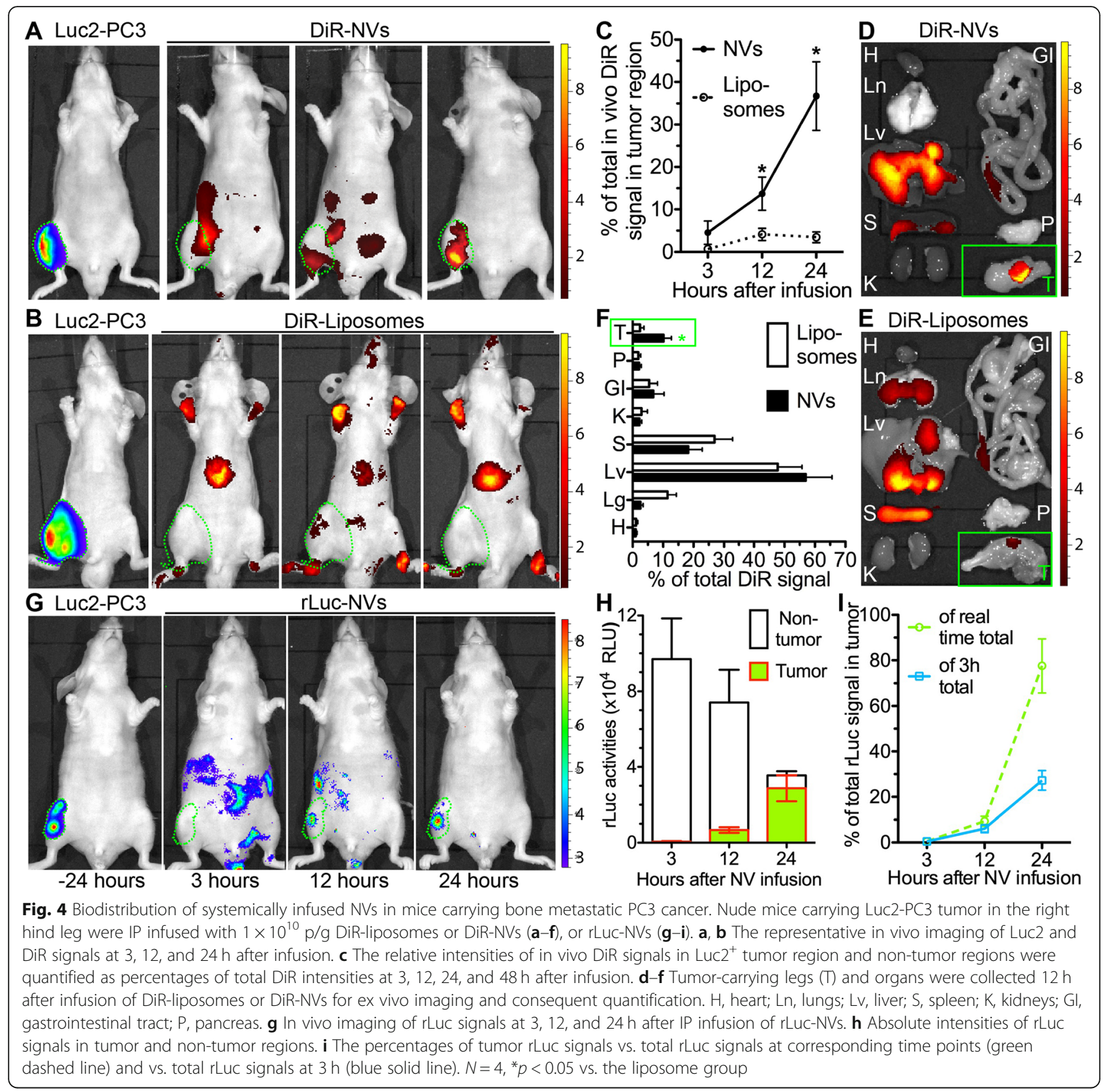

The tumor sizes were monitored every 4 days and Luc2 signals were imaged weekly. Compared with free Dxl and PBS treatment, NV-Dxl significantly decreased the Luc2 signal intensity and tumor volume after 2 weeks of treatment (Fig. $6 \mathrm{a}-\mathrm{C}$ ) and reduced the tumor weight at the end point of 24 days after treatment (Fig. 6d, e). Consistently, tumors from mice treated with NV-Dxl contain more TUNEL-positive cells than in free Dxl or PBS group, indicating an increase in apoptosis (Fig. S5). Meanwhile, the white blood cell (WBC) count at the end point was significantly decreased by free Dxl but not by NV-Dxl compared with the PBS group (Fig. 6f).
The establishment and progression of bone metastatic $\mathrm{PCa}$ was monitored by in vivo imaging of Luc2 bioluminescence weekly. When Luc2 signals were clearly detectable at the leg injected with Luc2-PC3 cells, mice were randomly grouped and intraperitoneally injected with PBS, free Dxl, or PEGylated Dxl-NVs at a dose of 5 $\mathrm{mg} / \mathrm{kg}$ body weight twice a week for 3 weeks. Compared with free Dxl and PBS treatment, NV-Dxl significantly decreased the Luc2 bioluminescence intensity after 2 weeks of treatment (Fig. 7a, b). Meanwhile, the white blood cell count at the end point of 21 days after treatment was significantly decreased by free Dxl but not by 


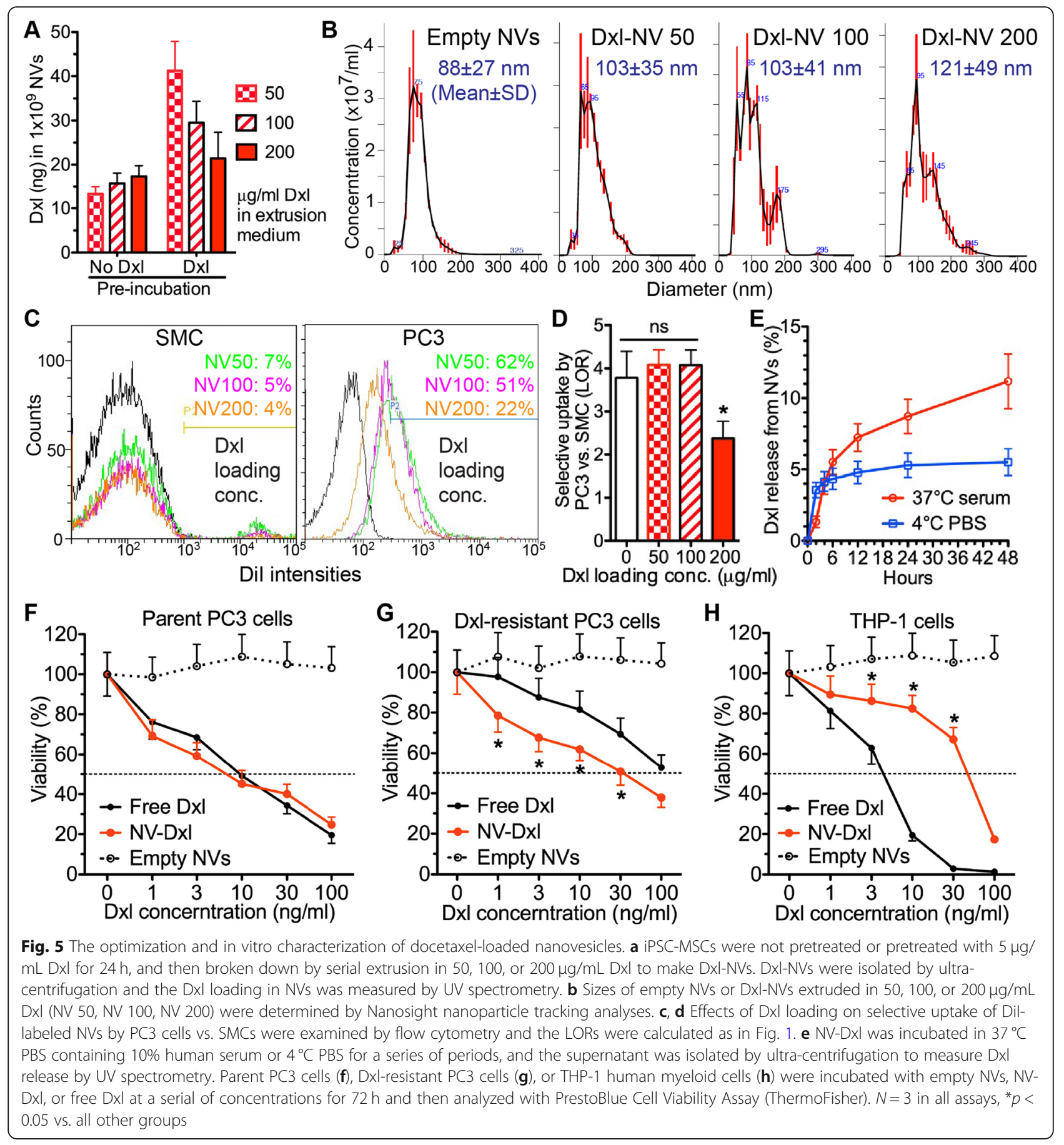

NV-Dxl compared with the PBS group (Fig. 7c). These data suggest that NV encapsulation can increase therapeutic effects of Dxl on metastatic PCa and decrease toxic effects of Dxl on white blood cells.

\section{Discussion}

We reported recently that iPSC-MSCs circumvent donor variations, expansion limitations, and the decreased expression of cancer-targeting surface molecules during expansion in tissue-derived MSCs; therefore, iPSCMSCs are a reliable source of cancer-targeting EVmimics [18]. Moreover, nanovesicles made from intact iPSC-MSCs have a much higher production yield and smaller and more consistent sizes compared with EVs and nanoghosts made from membrane-only ghost cells [18]. Here, we report that iPSC-MSC nanovesicles are more selectively taken up by prostate cancer $(\mathrm{PCa})$ cells than EVs, nanoghosts, and liposomes, the mainstream 

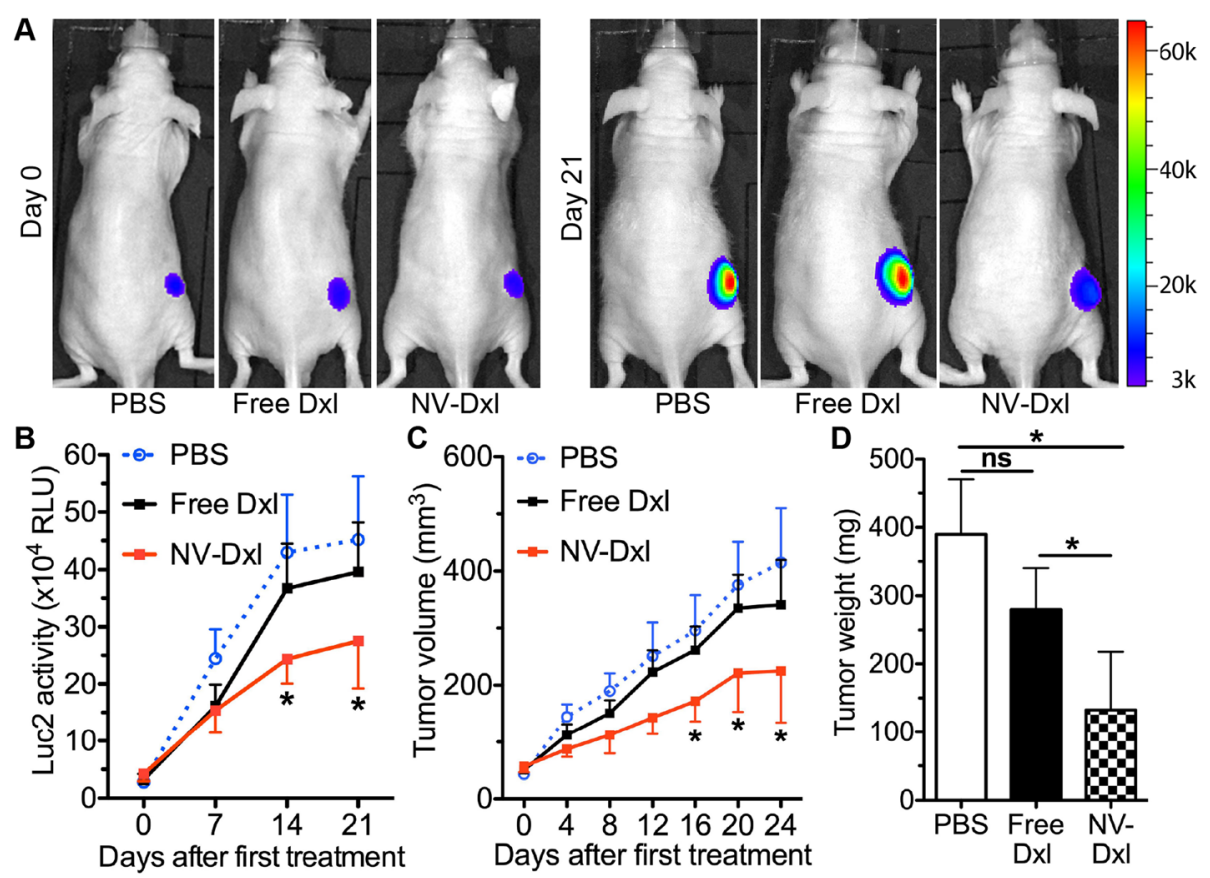

E
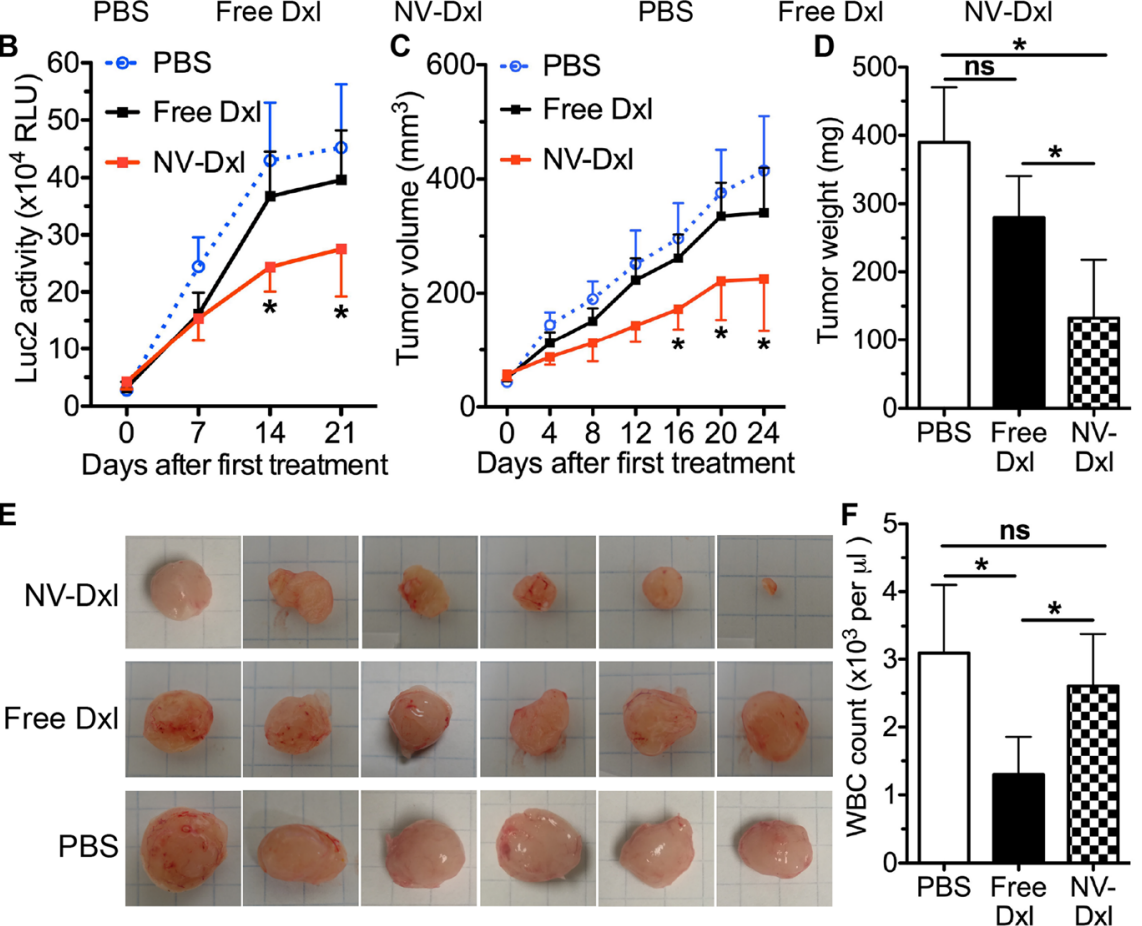

Fig. 6 Therapeutic effects of NV-Dxl in the mouse model of subcutaneous prostate cancer. a The representative in vivo Luc2 bioluminescence images before and by the end of treatments. $\mathbf{b}$ The quantification of weekly in vivo Luc2 bioluminescence intensities during treatment. $\mathbf{c}$ Tumor sizes were measured every 4 days till the end point of 24 days after treatment. $\mathbf{d}$, e Tumors were harvested and weighed at the end point. $\mathbf{f}$ The blood was collected at the end point to count white blood cell (WBC). $N=6,{ }^{*} p<0.05$ vs. the free Dxl group and the PBS group; ns, not significant

drug carrier for cancer nanomedicine. Moreover, nanovesicles can effectively deliver cytoplasmic components of iPSC-MSCs into $\mathrm{PCa}$ as indicated by the rLuc tracing assays. These advantages make nanovesicles a better choice than EVs and nanoghosts for targeting prostate cancer.

In both subcutaneous and bone metastatic PCa mouse models, human iPSC-MSC nanovesicles selectively accumulate in $\mathrm{PCa}$ with much higher efficiencies than liposomes. The PCa-targeting capacity of MSCs and MSC EV mimics is related to multiple surface proteins that interact with molecules abundant in PCa tumors $[8,9]$. Advanced PCa cells express high levels of Integrin $\alpha 3$, $\alpha 6$, and $\beta 1$ (ITGA3/A6/B1) [37, 38], EphA2 [39, 40], and connexins $(\mathrm{Cx})$ such as $\mathrm{Cx} 43 / 45$ [41] at their surface, and also increase levels of extracellular matrix (ECM) components including fibronectin (FN) [42], osteopontin
(OPN) [43], and hyaluronan [44] in tumor stroma. These over-expressed molecules contribute to the maintenance of cancer stem cells, metastasis, and poor clinical outcome. MSCs and their EVs or EV mimics carry multiple ligands of above molecules including Integrin $\alpha 4, \alpha 11$ and $\beta 1$ (ITGA4/A11/B1) [8, 9], CD44, CD63, TSPAN4, ICAM1, VCAM1, CD9, CD81, and Cx43 [18] (Fig. S4). We have confirmed the high levels of these ligands in our iPSC-MSCs and derived EV mimics [18]. Moreover, the common PTEN-deficiency in metastatic PCa cells including PC3 cells greatly promotes macropinocytosis [45], which in turn dramatically enhances uptake of adjacent EVs and EV-mimics [5]. These two mechanisms together make iPSC-MSC nanovesicles a promising carrier for the targeted delivery of anti-cancer agents into metastatic PCa. 

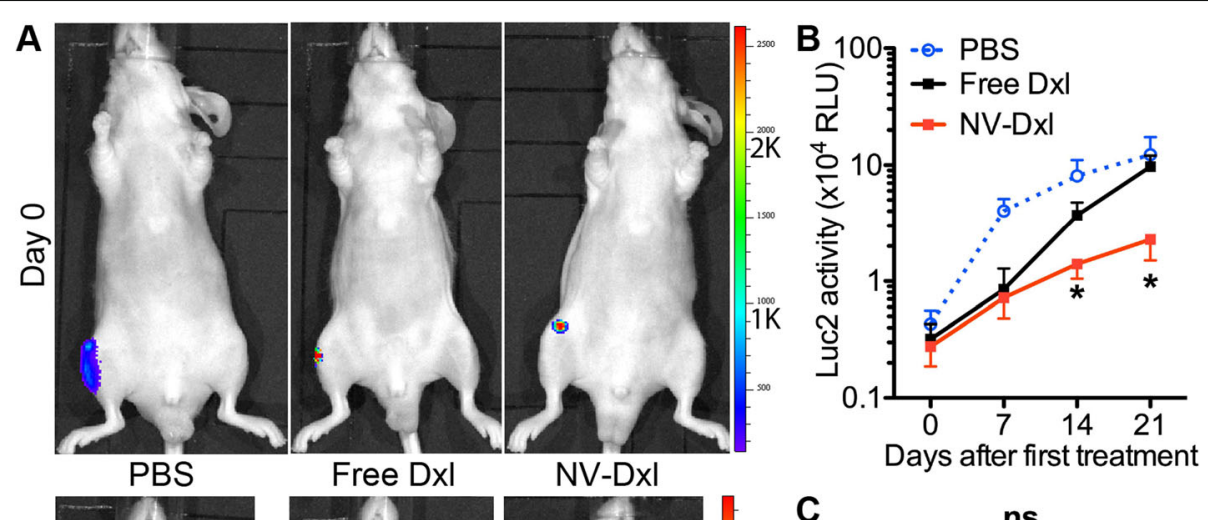

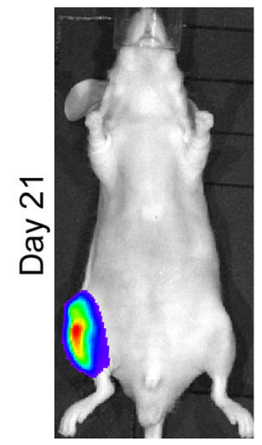

PBS

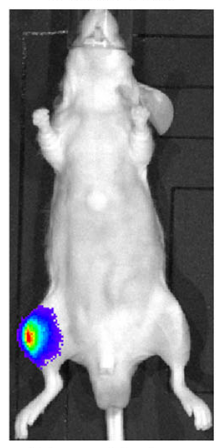

Free Dxl

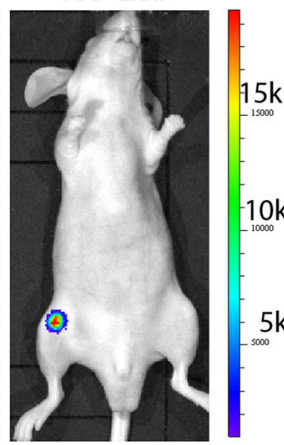

NV-Dxl
C

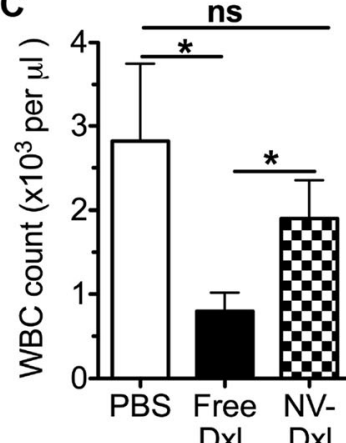

Fig. 7 Therapeutic effects of NV-Dxl in the mouse model of bone metastatic prostate cancer. a The representative in vivo Luc2 bioluminescence images before and by the end of treatments. $\mathbf{b}$ The quantification of weekly in vivo Luc2 bioluminescence intensities during treatments. $\mathbf{c}$ The blood was collected at the end point to count white blood cell (WBC). $N=6,{ }^{*} p<0.05$ vs. the free Dxl group and PBS group; ns, not significant

However, like EVs and all other nanoparticles, a large portion of nanovesicles accumulate in the mononuclear phagocytic system (MPS) organs despite the routine PEGylation. The PEG layer can reduce the binding of synthetic nanoparticles to phagocytes and prolong their circulation time and also inhibits active cancer targeting and cellular uptake mediated by targeting ligands and consequent intracellular delivery of payloads [46]. Since PCa express much higher levels of matrix metalloproteinases (MMP) than non-tumor tissues [47], the shielding of nanovesicles with MMP-sensitive PEG [48-50] is expected to lead to the cancer-specific degradation of PEG, which can enhance the uptake of nanovesicles by PCa cells while inhibiting that by MPS cells. Another promising approach is pretreating MSCs with proinflammatory cytokines before extrusion: in the mouse model of subcutaneous PC3 PCa, pretreatment of BM-MSCs with TNF $\alpha$ and IL1 $\beta$ significantly increased the accumulation of MSC nanoghosts in PCa but not in MPS organs, which is likely related to slight changes in expression levels of multiple membrane proteins [51].

The current guideline of International Society of Geriatric Oncology recommends docetaxel (Dxl) as the standard of care for metastatic PCa [31], but some patients cannot tolerate the toxicity of Dxl and all PCa patients will ultimately develop resistance to Dxl [33]. The encapsulation with nanovesicles significantly improved the cytotoxicity of Dxl on cultured Dxl-resistant PCa cells, which is likely through diverting enhanced drug efflux mediated by over-expressed or hyperactive membrane drug transporters [5]. In both subcutaneous and bone metastatic PCa mouse models, NV-Dxl significantly inhibited the tumor growth compared with the equal dose of free Dxl and resulted in much weaker toxicity on white blood cells. The increased therapeutic efficacy of NV-Dxl is likely related to both the enhanced delivery of Dxl into PCa tumors and the decreased Dxl efflux by membrane drug transporters in $\mathrm{PCa}$ cells.

\section{Conclusion}

Our data indicate that EV-mimetic nanovesicles made from iPSC-MSCs with a theoretically limitless expandability and consistent biological properties are a promising platform for targeted delivery of anti-cancer agents to improve treatment of metastatic prostate cancer.

\section{Supplementary Information}

Supplementary information accompanies this paper at https://doi.org/10. 1186/s13287-020-02097-5.

\section{Additional file 1.}

Additional file 2. 


\section{Abbreviations}

PCa: Prostate cancer; iPSCs: Induced pluripotent stem cells;

MSCs: Mesenchymal stem cells; EVs: Extracellular vesicles; NVs: Nanovesicles; SMCs: Smooth muscle cells; HUVECs: Human umbilical vein endothelial cells; PBS: Phosphate-buffered saline; LOR: Log odds ratios; PEG: Polyethylene glycol; PEGylation: A technique of covalent or noncovalent attachment of PEG to nanoparticles; FACS: Fluorescence-activated cell sorting; Dxl: Docetaxel; BM: Bone marrow; MPS: Mononuclear phagocytic system; Luc2: Firefly luciferase 2; rLuc: Renilla luciferase; RLU: Relative luminescence units; GFP: Green fluorescent protein; NT: Non-transduced; IP: Intraperitoneally; p/g: Particles/gram body weight; IC50: The half maximal inhibitory concentration; ANOVA: Analysis of variance; WBC: White blood cell; MMP: Matrix metalloproteinase

\section{Acknowledgements}

The Luc2-tdTomato lentiviral vector was kindly provided by Dr. Huiping Liu at Northwestern University, USA.

\section{Authors' contributions}

F.L. designed the studies and experiments. Q.Z. performed most experiments. B.H., J.K., and S.W. contributed to the preparation and characterization of nanovesicles. F.L. analyzed data and prepared the manuscript. The authors read and approved the final manuscript.

\section{Funding}

The work reported is supported by DoD CDMRP PCRP PC150083 (F.L.) and internal bridge fund provided by Texas A\&M University College of Medicine (F.L.).

\section{Availability of data and materials}

All data generated and/or analyzed during this study are included in this published article. The iPSC-MSCs and rLuc lentiviral vector will be distributed via Material Transfer Agreements (MTAs) generated and monitored by the Texas A\&M Office of Technology Commercialization.

\section{Ethics approval and consent to participate}

The animal study was approved by Texas A\&M University IACUC and Animal Care and Use Review Office (ACURO) of the US Army, and all procedures were in accordance with institutional guidelines.

\section{Consent for publication}

Not applicable.

\section{Competing interests}

Two of the authors, Fei Liu and Qingguo Zhao, share ownership over a patent entitled "Mesenchymal stem cells derived from induced pluripotent stem cells", which depicts some of the concepts presented herein. The patent was granted in USA on 2019-07-16 (US10351825B2) and is pending internationally (WO2016081032A3). The other three authors, Bo Hai, Jack Kelly, and Samuel Wu, declare that they have no conflict of interest.

Received: 9 July 2020 Accepted: 10 December 2020

Published online: 07 January 2021

\section{References}

1. Rawla P. Epidemiology of prostate cancer. World J Oncol. 2019;10(2):63-89 PubMed PMID: 31068988. Pubmed Central PMCID: 6497009.

2. Sturge J, Caley MP, Waxman J. Bone metastasis in prostate cancer: emerging therapeutic strategies. Nat Rev Clin Oncol. 2011;8(6):357-68 PubMed PMID: 21556025.

3. Bae YH, Park K. Targeted drug delivery to tumors: myths, reality and possibility. J Control Release. 2011;153(3):198-205 PubMed PMID: 21663778. Pubmed Central PMCID: 3272876.

4. Kroon J, Metselaar JM, Storm G, van der Pluijm G. Liposomal nanomedicines in the treatment of prostate cancer. Cancer Treat Rev. 2014;40(4):578-84 PubMed PMID: 24216226.

5. Mulcahy LA, Pink RC, Carter DR. Routes and mechanisms of extracellular vesicle uptake. J Extracellular Vesicles. 2014;3 PubMed PMID: 25143819. Pubmed Central PMCID: 4122821.

6. Kim MS, Haney MJ, Zhao Y, Mahajan V, Deygen I, Klyachko NL, et al. Development of exosome-encapsulated paclitaxel to overcome MDR in cancer cells. Nanomedicine. 2016;12(3):655-64 PubMed PMID: 26586551 Pubmed Central PMCID: 4809755.

7. Jang SC, Kim OY, Yoon CM, Choi DS, Roh TY, Park J, et al. Bioinspired exosomemimetic nanovesicles for targeted delivery of chemotherapeutics to malignant tumors. ACS Nano. 2013;7(9):7698-710 PubMed PMID: 24004438.

8. Toledano Furman NE, Lupu-Haber Y, Bronshtein T, Kaneti L, Letko N, Weinstein $E$, et al. Reconstructed stem cell nanoghosts: a natural tumor targeting platform. Nano Lett. 2013;13(7):3248-55 PubMed PMID: 23786263.

9. Kaneti L, Bronshtein T, Malkah Dayan N, Kovregina I, Letko Khait N, LupuHaber $Y$, et al. Nanoghosts as a novel natural nonviral gene delivery platform safely targeting multiple cancers. Nano Lett. 2016;16(3):1574-82 PubMed PMID: 26901695.

10. Siegel G, Kluba T, Hermanutz-Klein U, Bieback K, Northoff H, Schafer R. Phenotype, donor age and gender affect function of human bone marrowderived mesenchymal stromal cells. BMC Med. 2013;11:146 PubMed PMID: 23758701. Pubmed Central PMCID: 3694028.

11. Larson BL, Ylostalo J, Lee RH, Gregory C, Prockop DJ. Sox 11 is expressed in early progenitor human multipotent stromal cells and decreases with extensive expansion of the cells. Tissue Eng Part A. 2010;16(11):3385-94 PubMed PMID: 20626275. Pubmed Central PMCID: 2965191.

12. Redaelli S, Bentivegna A, Foudah D, Miloso M, Redondo J, Riva G, et al. From cytogenomic to epigenomic profiles: monitoring the biologic behavior of in vitro cultured human bone marrow mesenchymal stem cells. Stem Cell Res Ther. 2012;3(6):47 PubMed PMID: 23168092. Pubmed Central PMCID: 3580477.

13. de Witte SF, Franquesa M, Baan CC, Hoogduijn MJ. Toward development of imesenchymal stem cells for immunomodulatory therapy. Front Immunol. 2015;6:648 PubMed PMID: 26779185. Pubmed Central PMCID: 4701910.

14. Pennings I, van Dijk LA, van Huuksloot J, Fledderus JO, Schepers K, Braat AK, et al. Effect of donor variation on osteogenesis and vasculogenesis in hydrogel cocultures. J Tissue Eng Regen Med. 2019;13(3):433-45 PubMed PMID: 30650247. Pubmed Central PMCID: 6593839.

15. Kim S, Kim TM. Generation of mesenchymal stem-like cells for producing extracellular vesicles. World J Stem Cells. 2019;11(5):270-80 PubMed PMID: 31171955. Pubmed Central PMCID: 6545523.

16. Zhao Q, Gregory CA, Lee RH, Reger RL, Qin L, Hai B, et al. MSCs derived from iPSCs with a modified protocol are tumor-tropic but have much less potential to promote tumors than bone marrow MSCs. Proc Natl Acad Sci U S A. 2015; 112(2):530-5 PubMed PMID: 25548183. Pubmed Central PMCID: 4299223.

17. Ullah M, Kuroda Y, Bartosh TJ, Liu F, Zhao Q, Gregory C, et al. iPS-derived MSCs from an expandable bank to deliver a prodrug-converting enzyme that limits growth and metastases of human breast cancers. Cell Death Discovery. 2017;3: 16064 PubMed PMID: 28179988. Pubmed Central PMCID: 5292869.

18. Zhao Q, Hai B, Zhang X, Xu J, Koehler B, Liu F. Biomimetic nanovesicles made from iPS cell-derived mesenchymal stem cells for targeted therapy of triple-negative breast cancer. Nanomed Nanotechnol Biol Med. 2019; 102146. https://doi.org/10.1016/j.nano.2019.102146 [Epub ahead of print]. Epub 2019 Dec 26.

19. McNeill EP, Zeitouni S, Pan S, Haskell A, Cesarek M, Tahan D, et al. Characterization of a pluripotent stem cell-derived matrix with powerful osteoregenerative capabilities. Nat Commun. 2020;11(1):3025 PubMed PMID: 32541821. Pubmed Central PMCID: 7295745.

20. Yun Yl, Park SY, Lee HJ, Ko JH, Kim MK, Wee WR, et al. Comparison of the anti-inflammatory effects of induced pluripotent stem cell-derived and bone marrow-derived mesenchymal stromal cells in a murine model of corneal injury. Cytotherapy. 2017;19(1):28-35 PubMed PMID: 27840134.

21. Hai B, Shigemoto-Kuroda T, Zhao Q, Lee RH, Liu F. Inhibitory effects of iPSCMSCs and their extracellular vesicles on the onset of sialadenitis in a mouse model of Sjogren's syndrome. Stem Cells Int. 2018;2018:2092315 PubMed PMID: 29736173. Pubmed Central PMCID: 5875028

22. Liu H, Patel MR, Prescher JA, Patsialou A, Qian D, Lin J, et al. Cancer stem cells from human breast tumors are involved in spontaneous metastases in orthotopic mouse models. Proc Natl Acad Sci U S A. 2010;107(42):18115-20 PubMed PMID: 20921380. Pubmed Central PMCID: 2964232. Epub 2010/10/06. eng.

23. Aung T, Chapuy B, Vogel D, Wenzel D, Oppermann M, Lahmann M, et al. Exosomal evasion of humoral immunotherapy in aggressive B-cell lymphoma modulated by ATP-binding cassette transporter A3. Proc Natl Acad Sci U S A. 2011;108(37):15336-41 PubMed PMID: 21873242. Pubmed Central PMCID: 3174603

24. Wiklander OP, Nordin JZ, O'Loughlin A, Gustafsson Y, Corso G, Mager I, et al. Extracellular vesicle in vivo biodistribution is determined by cell source, 
route of administration and targeting. J Extracellular Vesicles. 2015;4:26316 PubMed PMID: 25899407. Pubmed Central PMCID: 4405624

25. Hammadi NI, Abba Y, Hezmee MNM, Razak ISA, Jaji AZ, Isa T, et al. Formulation of a sustained release docetaxel loaded cockle Shell-derived calcium carbonate nanoparticles against breast cancer. Pharm Res. 2017; 34(6):1193-203 PubMed PMID: 28382563.

26. O'Neill AJ, Prencipe M, Dowling C, Fan Y, Mulrane L, Gallagher WM, et al. Characterisation and manipulation of docetaxel resistant prostate cancer cell lines. Mol Cancer. 2011;10:126 PubMed PMID: 21982118. Pubmed Central PMCID: 3203088.

27. Euhus DM, Hudd C, LaRegina MC, Johnson FE. Tumor measurement in the nude mouse. J Surg Oncol. 1986;31(4):229-34 PubMed PMID: 3724177.

28. Tomayko MM, Reynolds CP. Determination of subcutaneous tumor size in athymic (nude) mice. Cancer Chemother Pharmacol. 1989;24(3):148-54 PubMed PMID: 2544306

29. Sun Q, Ojha T, Kiessling F, Lammers T, Shi Y. Enhancing tumor penetration of nanomedicines. Biomacromolecules. 2017;18(5):1449-59 PubMed PMID: 28328191. Pubmed Central PMCID: 5424079.

30. Bulbake U, Doppalapudi S, Kommineni N, Khan W. Liposomal formulations in clinical use: an updated review. Pharmaceutics. 2017 27;9(2). PubMed PMID: 28346375. Pubmed Central PMCID: 5489929

31. Boyle HJ, Alibhai S, Decoster L, Efstathiou E, Fizazi K, Mottet N, et al. Updated recommendations of the International Society of Geriatric Oncology on prostate cancer management in older patients. Eur J Cancer. 2019;116:116-36 PubMed PMID: 31195356.

32. Ramaswamy B, Puhalla S. Docetaxel: a tubulin-stabilizing agent approved for the management of several solid tumors. Drugs Today. 2006;42(4):265-79 PubMed PMID: 16703123.

33. Galletti G, Leach BI, Lam L, Tagawa ST. Mechanisms of resistance to systemic therapy in metastatic castration-resistant prostate cancer. Cancer Treat Rev. 2017:57:16-27 PubMed PMID: 28527407

34. Melzer C, Rehn V, Yang Y, Bahre H, von der Ohe J, Hass R. Taxol-loaded MSC-derived Exosomes provide a therapeutic vehicle to target metastatic breast Cancer and other carcinoma cells. Cancers. 2019 9;11(6). PubMed PMID: 31181850 . Pubmed Central PMCID: 6627807.

35. Kalimuthu S, Gangadaran P, Rajendran RL, Zhu L, Oh JM, Lee HW, et al. A new approach for loading anticancer drugs into mesenchymal stem cellderived exosome mimetics for cancer therapy. Front Pharmacol. 2018;9:1116 PubMed PMID: 30319428. Pubmed Central PMCID: 6168623.

36. Wang Q, Alshaker H, Bohler T, Srivats S, Chao Y, Cooper C, et al. Core shell lipid-polymer hybrid nanoparticles with combined docetaxel and molecular targeted therapy for the treatment of metastatic prostate cancer. Sci Rep. 2017; 7(1):5901 PubMed PMID: 28724986. Pubmed Central PMCID: PMC5517417.

37. Kurozumi A, Goto Y, Matsushita R, Fukumoto I, Kato M, Nishikawa R, et al. Tumor-suppressive microRNA-223 inhibits cancer cell migration and invasion by targeting ITGA3/TGB1 signaling in prostate cancer. Cancer Sci. 2016;107(1): 84-94 PubMed PMID: 26509963. Pubmed Central PMCID: 4724812.

38. Yang J, Fizazi K, Peleg S, Sikes CR, Raymond AK, Jamal N, et al. Prostate cancer cells induce osteoblast differentiation through a Cbfa1-dependent pathway. Cancer Res. 2001;61(14):5652-9 PubMed PMID: 11454720.

39. Zeng G, Hu Z, Kinch MS, Pan CX, Flockhart DA, Kao C, et al. High-level expression of EphA2 receptor tyrosine kinase in prostatic intraepithelial neoplasia. Am J Pathol. 2003;163(6):2271-6 PubMed PMID: 14633601. Pubmed Central PMCID: 1892376.

40. Wang $\mathrm{H}$, Lin $\mathrm{H}$, Pan J, Mo C, Zhang F, Huang B, et al. Vasculogenic mimicry in prostate cancer: the roles of EphA2 and PI3K. J Cancer. 2016;7(9):1114-24 PubMed PMID: 27326255. Pubmed Central PMCID: 4911879.

41. Boucher J, Monvoisin A, Vix J, Mesnil M, Thuringer D, Debiais F, et al. Connexins, important players in the dissemination of prostate cancer cells. Biochim Biophys Acta. 2018;1860(1):202-15 PubMed PMID: 28693897.

42. Das DK, Naidoo M, llboudo A, Park JY, Ali T, Krampis K, et al. miR-1207-3p regulates the androgen receptor in prostate cancer via FNDC1/fibronectin. Exp Cell Res. 2016; 348(2):190-200 PubMed PMID: 27693493. Pubmed Central PMCID: 5077722.

43. Zhao H, Chen Q, Alam A, Cui J, Suen KC, Soo AP, et al. The role of osteopontin in the progression of solid organ tumour. Cell Death Dis. 2018; 9(3):356 PubMed PMID: 29500465. Pubmed Central PMCID: 5834520

44. Josefsson A, Adamo H, Hammarsten P, Granfors T, Stattin P, Egevad L, et al. Prostate cancer increases hyaluronan in surrounding nonmalignant stroma, and this response is associated with tumor growth and an unfavorable outcome. Am J Pathol. 2011:179(4):1961-8 PubMed PMID: 21854754. Pubmed Central PMCID: 3181394.
45. Kim SM, Nguyen TT, Ravi A, Kubiniok P, Finicle BT, Jayashankar V, et al. PTEN deficiency and AMPK activation promote nutrient scavenging and anabolism in prostate cancer cells. Cancer Discov. 2018;8(7):866-83 PubMed PMID: 29572236. Pubmed Central PMCID: 6030497.

46. Yao Q, Kou L, Tu Y, Zhu L. MMP-responsive 'Smart' drug delivery and tumor targeting. Trends Pharmacol Sci. 2018;39(8):766-81 PubMed PMID: 30032745.

47. Xie T, Dong B, Yan Y, Hu G, Xu Y. Association between MMP-2 expression and prostate cancer: a meta-analysis. Biomedical Reports. 2016;4(2):241-5 PubMed PMID: 26893846. Pubmed Central PMCID: 4734094.

48. Dai Z, Yao Q, Zhu L. MMP2-sensitive PEG-lipid copolymers: a new type of tumor-targeted P-glycoprotein inhibitor. ACS Appl Mater Interfaces. 2016; 8(20):12661-73 PubMed PMID: 27145021.

49. Yao Q, Liu Y, Kou L, Tu Y, Tang X, Zhu L. Tumor-targeted drug delivery and sensitization by MMP2-responsive polymeric micelles. Nanomedicine. 2019;19:71-80.

50. Yao Q, Choi JH, Dai Z, Wang J, Kim D, Tang X, et al. Improving tumor specificity and anticancer activity of dasatinib by dual-targeted polymeric micelles. ACS Appl Mater Interfaces. 2017;9(42):36642-54.

51. Lupu-Haber Y, Bronshtein T, Shalom-Luxenburg H, D'Atri D, Oieni J, Kaneti L, et al. Pretreating mesenchymal stem cells with cancer conditioned-media or proinflammatory cytokines changes the tumor and immune targeting by nanoghosts derived from these cells. Advanced Healthcare Materials. 2019; 8(10):e1801589 PubMed PMID: 30963725.

\section{Publisher's Note}

Springer Nature remains neutral with regard to jurisdictional claims in published maps and institutional affiliations.
Ready to submit your research? Choose BMC and benefit from:

- fast, convenient online submission

- thorough peer review by experienced researchers in your field

- rapid publication on acceptance

- support for research data, including large and complex data types

- gold Open Access which fosters wider collaboration and increased citations

- maximum visibility for your research: over $100 \mathrm{M}$ website views per year

At BMC, research is always in progress.

Learn more biomedcentral.com/submissions 